\title{
ENXERTIA PRECOCE DA GRAVIOLEIRA (Annona muricata L.) ${ }^{1}$
}

\author{
MÁRIO COUQUITI KITAMURA² \& EURICO EDUARDO PINTO LEMOS ${ }^{3}$
}

\begin{abstract}
RESUMO - Visando a determinar o efeito da idade do porta-enxerto sobre a porcentagem de enxertos "pegos", foi desenvolvido um experimento com esta finalidade no Campo Experimental da Universidade Federal de Alagoas-UFAL, no período de julho a dezembro de 2001. Os porta-enxertos utilizados foram obtidos de sementes da gravioleira Morada, as quais foram enxertadas com a gravioleira Gigante das Alagoas. O método de enxertia empregado foi por garfagem de topo em fenda cheia, e o delineamento experimental usado foi o de blocos ao acaso, com cinco repetições e dezesseis plantas por unidade experimental. Foram avaliados a percentagem média de pegamento do enxerto aos 60 dias após a enxertia, diâmetro do caule e altura dos porta-enxertos em quatro idades distintas $(40 ; 55 ; 70$ e 85 dias após a emergência). Verificou-se que o percentual de pegamento do enxerto aumentou com a idade dos porta-enxertos, no qual a idade de 85 dias após a emergência foi superior às demais, apresentando $82 \%$ de pegamento. Aos 40 dias após a emergência, não houve pegamento, e somente a partir de 55 dias após a emergência, constatou-se o pegamento do enxerto, ou seja, com diâmetro médio do caule acima de $2,21 \mathrm{~mm}$.
\end{abstract}

Termos para indexação: garfagem, propagação vegetativa, porta-enxertos, fruta tropical

\section{EARLY GRAFTING IN SOURSOP (Annona muricata L.)}

ABSTRACT - In order to determinate the age effect on soursop tree grafting, an experiment was carried out at the Universidade Federal de Alagoas, Brazil during the period of July to December 2001. The performance of four ages of the rootstocks for soursop tree was evaluated in 40, 55, 70 and 85 days after emergence. The rootstocks utilized were obtained from seeds of the soursop tree "Morada", which were grafted with the soursop tree "Gigante das Alagoas". The grafting utilized was by top cleft graft methods and the experimental design utilized was randomized blocks with five replicates and sixteen plants per experimental unit. The evaluations consisted of percentage of grafting technique success at 60 days after grafting, stem diameter and height of the soursop seedlings for each ages. It was verified that the percent of success of the graft increased with the rootstocks ages. The age of 85 days after emergence showed a better performance than the others, presenting $82 \%$ of grafting success. At 40 days after emergence, there was no success and only after 55 days of emergence and with stem diameter above $2,21 \mathrm{~mm}$ was obtained success of the grafting. Index terms: cleft graft, asexual propagation, seedlings, tropical fruit, rootstocks.

A enxertia constitui-se em prática mundialmente consagrada na fruticultura, sendo usada em larga escala, nas principais espécies frutíferas, tanto de regiões de clima temperado como de clima tropical, e sua utilização permite a reprodução integral do genótipo que apresenta características desejáveis. Como vantagem adicional, a propagação por enxertia possibilita que as plantas entrem em fase de produção mais cedo (Carvalho et al., 2000).

As pesquisas com gravioleira no Brasil são relativamente recentes e, portanto, poucos resultados práticos foram efetivamente alcançados. Na área de propagação vegetativa, sobretudo a enxertia, são escassos os resultados de pesquisa e, algumas vezes, muito contrastantes devido às diferentes condições climáticas dos locais experimentados, além da influência da idade, do estado fisiológico e fitossanitário dos porta-enxertos e das plantas matrizes fornecedoras dos garfos e borbulhas (Pádua, 1983).

Normalmente na propagação vegetativa, utilizam-se portaenxertos com 8 a 12 meses de idade, apresentando diâmetro médio do caule em torno de $1,0 \mathrm{~cm}$ na zona operatória, isto é, na altura de 20 a $25 \mathrm{~cm}$ do coleto da planta, enxertando-os pelos métodos de enxertia por borbulhia ou por garfagem (Melo et al., 1983; Ledo \& Fortes, 1991; Genú et al., 1992; Freitas, 1997). Conseqüentemente, as mudas deverão estar prontas para plantio no campo com idade acima de 12 meses (considerando 3 a 4 meses após a enxertia), exigindo, portanto, recipiente com capacidade volumétrica de 6 a $8 \mathrm{~kg}$ de substrato, maior demanda de mão-de-obra, insumos, água para irrigação, área para viveiro, resultando em maior custo de produção.

Estudos indicam que a idade do porta-enxerto determina qual o tipo de enxertia na propagação da gravioleira. Lederman et al. (1997) verificaram que o índice de pegamento do enxerto, utilizando portaenxertos com 12 meses de idade, foi superior aos de 10 meses, obtendo 97,5\% de "pega", enxertando-os pelo método de borbulhia em placa. Outros trabalhos conduzidos por Ledo e Fortes (1991), estudando nove métodos de enxertia da gravioleira em porta-enxertos com 12 meses de idade, obtiveram maiores índices de pegamento do enxerto pelo método de garfagem à inglesa simples e garfagem de topo em fenda cheia.

Na enxertia precoce, busca-se utilizar porta-enxertos com idade bem mais jovem do que aqueles utilizados normalmente; conseqüentemente, pode-se reduzir significativamente o custo de produção, em função da redução do volume de substrato, materiais de consumo e do tempo de permanência das mudas no viveiro, além de outras vantagens, como facilidade no manuseio, intercâmbio de germoplasma e redução no custo do transporte. Nesse sentido, foi instalado um experimento em julho de 2001, no Campo Experimental da Universidade Federal de Alagoas-UFAL, no município de Maceió-AL, com o objetivo de viabilizar a enxertia precoce da gravioleira. Este trabalho foi conduzido em condições de viveiro, tendo sido utilizados a gravioleira 'Morada' como porta-enxerto e a cultivar comercial 'Gigante das Alagoas' como enxerto.

As sementes utilizadas para a formação dos porta-enxertos foram extraídas de frutos recém-colhidos da gravioleira 'Morada', semeadas diretamente em recipientes tipo tubetes de plástico preto, rígido, de formato cônico, com capacidade volumétrica de 0,32 litro. Esses tubetes foram dispostos em fileiras duplas $(50 \mathrm{~cm} \mathrm{x} 7 \mathrm{~cm} \mathrm{x} 7 \mathrm{~cm})$ sobre um suporte de ferro, de forma que mantivesse os tubetes a $5 \mathrm{~cm}$ acima do piso, visando à poda natural das raízes pelo vento e a evitar possível contaminação por fungos do solo. Inicialmente, os porta-enxertos desenvolveram-se sob sombreamento de 50\%, sendo irrigados por microaspersão. Posteriormente, por ocasião da enxertia, essas plantas foram transferidas para ambiente com $80 \%$ de sombreamento, visando a fornecer melhores condições para o pegamento do enxerto.

$\mathrm{O}$ delineamento experimental utilizado foi o de blocos casualizados, com quatro tratamentos, cinco repetições e dezesseis plantas por parcela, perfazendo um total de 320 plantas. Os tratamentos consistiram em quatro idades de porta-enxertos (40; 55; 70 e 85 dias após a emergência-DAE).

O substrato consistiu na mistura de $50 \%$ de terra de barranco e

\footnotetext{
${ }^{1}$ (Trabalho 093/2003). Recebido: 13/06/2003. Aceito para publicação: 26/03/2004. Extraído da Tese apresentada pelo primeiro autor junto à Universidade Federal de Lavras (UFLA) para a obtenção do título de Doutor.

2 Eng. Agr ${ }^{\circ}$. M.Sc. Dr. Prof. Adjunto, UFRR, km 12, Boa Vista-RR, CEP 69.301-970,. e-mail: couquiti@uol.com.br.

${ }^{3}$ Eng.Agr ${ }^{\circ}$. M.Sc.Ph.D.,Prof. Adjunto UFAL,BR 104, km 14, Maceió-AL, CEP 57072-970, e-mail: eepl@uol.com.br.
} 
$50 \%$ de composto orgânico (torta de filtro de cana-de-açúcar), ambos peneirados com malha de $10 \mathrm{~mm}$. Foram adicionados $2,5 \mathrm{~kg}$ de calcário dolomítico (PRNT 100\%), $5 \mathrm{~kg}$ de superfosfato simples $\left(18 \% \mathrm{P}_{2} \mathrm{O}_{5}\right)$ e $1 \mathrm{~kg}$ de cloreto de potássio $\left(60 \% \mathrm{~K}_{2} \mathrm{O}\right)$ por $\mathrm{m}^{3}$ da mistura. $\mathrm{O}$ nitrogênio foi aplicado em cobertura, utilizando-se como fonte da uréia $(45 \% \mathrm{~N})$ diluída a $0,3 \%$ e aplicada a partir de 30 dias após a emergência das plântulas.

O método de enxertia empregado foi por garfagem de topo em fenda cheia, e os garfos utilizados foram coletados no ápice dos ramos das plantas adultas do clone da gravioleira 'Gigante das Alagoas', apresentando diâmetro semelhante ao dos porta-enxertos. Com sete dias de antecedência da enxertia, foi feita a "toalete" dos garfos, retirando suas folhas para induzir o intumescimento das gemas e proporcionar melhor pegamento dos enxertos.

O procedimento para a enxertia consistiu nas seguintes etapas:

a) Decapitação do porta-enxerto a uma altura de $4 \mathrm{~cm}$, a partir do colo da planta;

b) No porta-enxerto decapitado, colocou-se um anel de canudo plástico de refrigerante com $2 \mathrm{~cm}$ de comprimento e diâmetro que variou de $3,5 \mathrm{~mm}$ a $6 \mathrm{~mm}$, ligeiramente superior ao do caule da planta na região de incisão;

c) Em seguida, fez-se um corte vertical com $0,7 \mathrm{~cm}$ de comprimento no topo do porta-enxerto;

d) No garfo, fez-se um corte em bisel duplo, em forma de cunha, com $0,7 \mathrm{~cm}$ de comprimento na extremidade inferior do garfo;

e) Em seguida, efetuou-se a inserção do garfo sobre a fenda produzida no porta-enxerto, e manualmente fez-se o ajuste do anel de canudo plástico de forma que a justaposição enxerto/ porta-enxerto fosse perfeita;

f) Finalmente, fez-se a cobertura do enxerto com saco plástico incolor e transparente, com dimensões de 4 x $16 \mathrm{~cm}$, preso logo abaixo do enxerto.

Os sacos plásticos de cobertura do enxerto foram retirados aos 30 dias após a enxertia. Não foi necessário fazer a remoção dos anéis plásticos, pois estes se romperam naturalmente.

Foram avaliados o diâmetro e a altura dos porta-enxertos aos 40; 55; 70 e 85 dias após a emergência, e a porcentagem de enxertos "pegos", aos 60 dias após a enxertia. Os dados obtidos foram submetidos à análise de variância, sendo as médias comparadas pelo teste de Tukey, a $5 \%$ de probabilidade.

A idade do porta-enxerto teve efeito significativo $(\mathrm{P} \varangle 0,05)$ sobre o pegamento do enxerto (Tabela 1). Verificou-se que a idade de 85 dias após a emergência (DAE) foi superior às demais quanto ao pegamento do enxerto, proporcionando porcentagem média de pegamento de $82 \%$, o qual foi semelhante ao obtido por Ferreira \& Clemente (1987), Ledo \& Fortes (1991), Lederman et al. (1997), em trabalhos de enxertia da gravioleira por borbulhia, utilizando como porta-enxerto a própria gravioleira com 12 meses de idade.

TABELA 1 - Análise de variância para diâmetro do caule e altura dos porta-enxertos aos 40; 55; 70 e 85 dias após a emergência e pegamento do enxerto aos 60 dias após a enxertia, por garfagem no topo em fenda cheia.

\begin{tabular}{|c|c|c|c|c|}
\hline & & QM e & Significância & \\
\hline FV & GL & $\begin{array}{c}\text { Pegamento aos } \\
60 \text { dias }\end{array}$ & Diâmetro & Altura \\
\hline Blocos & 4 & 2,70 & 0,021641 & 0,373386 \\
\hline Idade & 3 & $159,25 *$ & $2,204506^{*}$ & $62,569335^{*}$ \\
\hline Erro & 12 & 3,33 & 0,011245 & 0,29288 \\
\hline Total & 19 & & & \\
\hline $\mathrm{CV}(\%)$ & & 35,45 & 4,28 & 3,82 \\
\hline $\begin{array}{l}\text { Média } \\
\text { geral }\end{array}$ & & 5,15 & 2,47 & 14,17 \\
\hline
\end{tabular}

* significativo a 5\% de probabilidade

Em porta-enxerto com a idade de 40 dias após a emergência, não houve pegamento do enxerto; no entanto, com a idade de 55 dias após a emergência, verificou-se porcentagem média de pegamento de $22,5 \%$, o qual não diferiu estatisticamente da idade de 70 dias após a emergência. Portanto, aos 55 e 70 dias após a emergência, o índice de pegamento do enxerto foi baixo, sendo economicamente inviável a sua recomendação para a produção comercial de mudas de gravioleira. A idade do porta-enxerto, que resultou em maior índice de pegamento, foi aos 85 dias após a emergência, quando apresentou porcentagem média de pegamento de $82 \%$ (Figura 1).

É importante ressaltar que, neste experimento, a enxertia foi realizada em porta-enxertos jovens com idades variando entre 40 a 85 dias após a emergência, cujos diâmetros médios na zona operatória, isto é, a $4 \mathrm{~cm}$ de altura do coleto da planta, se apresentavam entre 1,71 a $3,25 \mathrm{~mm}$ (Figura 2). Em função da precocidade dos porta-enxertos, houve muita dificuldade na operação da enxertia devido ao manuseio de caules finos e tenros. Com o aprimoramento desta técnica, é possível melhorar o índice de pegamento dos enxertos.

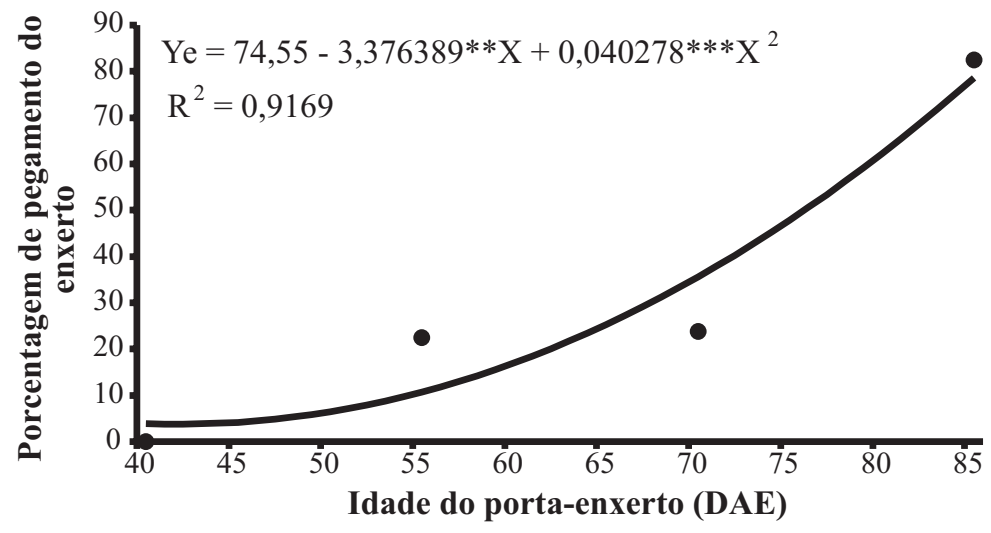

$* *$; *** Significativo a $1 \%$ e $0,1 \%$ de probabilidade, respectivamente, pelo teste de T

FIGURA 1 - Porcentagem média de pegamento do enxerto aos 60 dias após a enxertia, por garfagem no topo em fenda cheia.

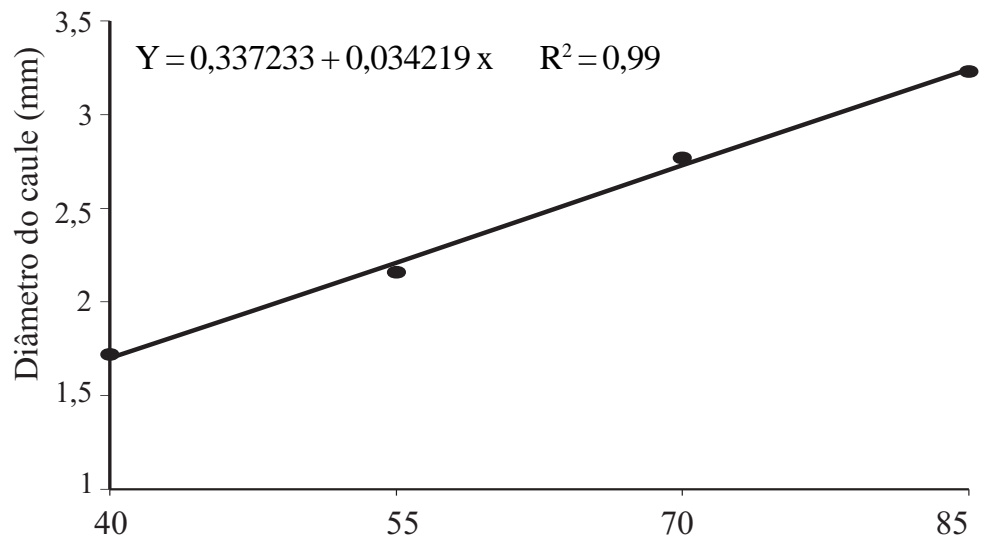

Idade dos porta-enxertos (DAE)

FIGURA 2 - Diâmetro médio do caule dos porta-enxertos da gravioleira 'Morada'.

\section{REFERÊNCIASBIBLIOGRÁFICAS}

CARVALHO, J.E.U.de; RIBEIRO, M.A.C.; NASCIMENTO, W. M. O. do; MULLER, C.N. Enxertia da gravioleira (Annona muricata L.) em porta-enxertos dos gêneros Annona e Rollinia. Embrapa Amazônia Oriental, 2000. 4p. (Comunicado Técnico, 27).

FERREIRA, S. A. do N.; CLEMENTE, C. Avaliação de diferentes portaenxertos para a gravioleira na Amazônia Central. I - Métodos de enxertia. In: CONGRESSO BRASILEIRO DE FRUTICULTURA, 9., 1987, Campinas-SP. Anais... Campinas-SP: Sociedade Brasileira de Fruticultura, 1987. v.2, p.475-479.

FREITAS, G. B. Propagação, florescimento, frutificação e produção da gravioleira (Annona muricata L.). Viçosa-MG: UFV,1997. 87p. Tese 
(Doutorado em fitotecnia) - Universidade Federal de Viçosa, Viçosa, 1997.

GENÚ, P. J. de C.; RAMOS, V. H. V.; JUNQUEIRA, N. T. V.; PINTO, A.C. de Q. Instruções para a formação de mudas de gravioleira por enxertia. Planaltina: EMBRAPA-CPAC, 1992. 14p. (Circular Técnica, 28).

LEDO, A. da S.; FORTES, J. M. Avaliação de métodos de enxertia para a gravioleira em Viçosa-MG. Revista Brasileira de Fruticultura, Cruz das Almas, V.13, N.1, p. 63-66, 1991.
LEDERMAN, I. E.; SILVA, M. F. F. da; BEZERRA, J. E. F.; SANTOS, V. F. Influência da idade do porta-enxerto e do tipo de enxertia na propagação da gravioleira. Pesquisa Agropecuária Brasileira, Brasília, v. 32, n. 6, p.613-615, 1997.

MELO, G. S.; GONZAGA NETO, L.; MOURA, R. I. M. Cultivo da gravioleira (Annona muricata L.). Recife: IPA, 1983. 3 p.(Instruções técnicas, 13)

PÁDUA, T. Propagação de árvores frutíferas. Informe agropecuário, Belo Horizonte, v.9, n.101, p.11-9, 1983. 